\title{
Taxonomic Notes on Some Cultivable Fishes Found in the Water Bodies of Southern Kerala
}

\author{
Mathews Plamoottil \\ Asst. Professor \& HOD, Dept. of Zoology, \\ Baby John Memorial Govt. College, Chavara, Kollam, Kerala
}

\begin{abstract}
The present study was conducted to analyse the systematic details of cultivable fishes residing in the aquatic bodies of Southern Kerala, India. Culture fishes collected from different sites of various water bodies of Kerala; 20 species of fishes belong to the genera Systomus, Catla, Labeo, Cirrhinus, Cyprinus, Pangasinodon, Clarias, Wallago, Heteropneustes Oreochromis, Osphronemus, Lates, Anabas, Etroplus, Pristolepis and Channa were collected from various locations. They were examined for meristic counts and morphometric characters and undergone detailed taxonomic studies.
\end{abstract}

Keywords: Systematics, Kerala, Meristic counts, Metric characters

\begin{abstract}
Abbreviations: D-Dorsal fin rays; P-Pectoral fin rays; V-Ventral fin rays; A-Anal fin rays; C-Caudal fin rays; LLS-Lateral line scales; LL/D-Scales between lateral line and dorsal fin; LL/V-Scales between lateral line and ventral fin; LL/A-Scales between lateral line and ventral fin; CPS-Circumpeduncular scales; PDSPre dorsal scales; PRPLS-Pre pelvic scales; PRAS-Pre anal scales; BDD-Body depth at dorsal fin origin; BDA-Body depth at anal fin origin; BWD- Body width at dorsal fin; BWA-Body width at anal fin; HD- head depth; PRD- Pre dorsal length; POD-Post dorsal length; PRPL-Pre pelvic length; LP- Length of pectoral fin; LD- Length of dorsal fin; LPL- Length of pelvic fin; LA- Length of anal fin; LC- Length of caudal fin; LBDLength of base of dorsal fin; LBA- Length of base of anal fin; DP-PL-Distance from pectoral to pelvic fin; DPL-A-Distance from pelvic to anal fin; DA-C-Distance from anal to caudal fin; LCP-Length of caudal peduncle; DCP-Depth of caudal peduncle; DVV-Distance from ventral to vent; DAV-Distance from anal to vent; HD-Head depth; HW-Head width; ED-Eye diameter; STL-Snout length; IOW-Inter orbital width; INWInter narial width; DOC-D-Distance from occiput to dorsal fin; DOC-ST-Disance from occiput to snout; POC-D-Pre occipital distance; HL-STL- Head length excluding snout.
\end{abstract}

\section{INTRODUCTION}

Many economically valuable fishes are cultivated in various man- made water bodies of Kerala. Most of them are indigenous freshwater fishes; but some are exotic fishes. They are mainly cyprinids, silurids and percomorphs. Domesticated fishes must bear certain good qualities; superior nutritional value, agreeable taste, fast growth rate, enhanced disease resistance, high market demand and high price are the desirable traits of cultivated fishes [1], [2].

Many studies were conducted on the various rearing methods of freshwater fishes of Kerala. But taxonomic studies on the cultivable fishes of the state are rare. It is an endeavor to analyze the taxonomic details of the commonly reared fishes and also those which can be cultivated due to their favorable traits.

\section{Materials AND Methods}

Caste nets, gill nets and dip nets were used for collecting fishes. Gill nets were used in areas where water body was deep. Cast nets were used in areas where water is shallow. Fishes collected at intervals from different localities during the morning times. At the time of monsoon ("oothayilakam"), 'mada vala' was used for collecting small to medium sized fishes. Captured fishes were fixed in nine percent formalin. After one month of preservation fixed fishes were taken out and taxonomically identified based mainly on meristic, morphometric and descriptive characters. Methods and measurements used are as per Jayaram [3-8]. 


\section{ReSUlts AND DiscuSSION}

Twenty species of fishes were collected from various locations of southern Kerala (Table $1 \&$ Fig 120). Of these, Cyprinus carpio communis, Pangasinodon hypothalmus, Clarias gariepinus, Oreochromis mossambica and Osphronemus gorami are exotic fishes. In addition to these, Anabas testeudinus, Lates calcarifer and Channa micropeltes were also originally described from foreign countries. All these cultivable fishes are economically important and popular food fishes.

\subsection{Catla catla (Hamilton- Buchanan)}

Catla Valenciennes IN: Cuvier \& Valenciennes, 1844, Hist. Nat. Poss., 18: 410 (type species, Catla buchanani Valenciennes= Cyprinus catla Hamilton- Buchanan, type by monotypy).

Synonyms: Cyprinus catla; Catla buchanani

Diagnosis: Barbels absent; mouth superior; upper lip absent; dorsal fin long with 13 branched rays and devoid of any spine; lateral line complete with 39 scales; pectoral fin reach pelvic fin origin; pelvic fin reach anal opening; anal fin fairly reach caudal base.

Table1. Author, locality and classification of cultivable fishes of southern Kerala

\begin{tabular}{|c|c|c|c|c|c|}
\hline Sl. No & Name of fish & Author & Type locality & Order & Family \\
\hline 1 & Catla catla & Hamilton- Buchanan & West Bengal & Cypriniformes & Cyprinidae \\
\hline 2 & Labeo rohita & Hamilton- Buchanan & Gangetic Provinces & Cypriniformes & Cyprinidae \\
\hline 3 & Labeo gonius & Hamilton- Buchanan & W. Bengal & Cypriniformes & Cyprinidae \\
\hline 4 & Cirrhina mrigala & Hamilton- Buchanan & Gangetic Provinces & Cypriniformes & Cyprinidae \\
\hline 5 & Cirrhina cirrhosus & Bloch & Cauvery River & Cypriniformes & Cyprinidae \\
\hline 6 & $\begin{array}{c}\text { Cyprinus carpio } \\
\text { communis }\end{array}$ & Linnaeus & Europe & Cypriniformes & Cyprinidae \\
\hline 7 & Systomus sarana & Hamilton Buchanan & Bengal & Cypriniformes & Cyprinidae \\
\hline 8 & $\begin{array}{c}\text { Pangasinodon } \\
\text { hypothalamus }\end{array}$ & Sauvage & unknown & Siluriformes & Pangasidae \\
\hline 9 & Clarias gariepinus & Burchell & Africa & Siluriformes & Clariidae \\
\hline 10 & Wallago attu & Bloch \& Schneider & Malabar & Siluriformes & Siluridae \\
\hline 11 & $\begin{array}{c}\text { Heteropneustes } \\
\text { fossilis }\end{array}$ & Bloch & Tranquebar & Siluriformes & Heteropneustidae \\
\hline 12 & $\begin{array}{c}\text { Oreochromis } \\
\text { mossambica }\end{array}$ & Peters & Mozambique & Perciformes & Cichlidae \\
\hline 13 & $\begin{array}{c}\text { Osphronemus } \\
\text { gorami }\end{array}$ & Lacepede & Mauritius & Perciformes & Osphronemidae \\
\hline 14 & Anabas testeudineus & Bloch & Java & Perciformes & Anabantidae \\
\hline 15 & Etroplus suratensis & Bloch & Surat & Perciformes & Cichlidae \\
\hline 16 & Lates calcarifer & Bloch & Indonesia & Perciformes & Centropomidae \\
\hline 17 & $\begin{array}{c}\text { Pristolepis } \\
\text { rubripinnis }\end{array}$ & Britz et al. & Edathua & Perciformes & Pristolepididae \\
\hline 19 & Channa marulius & Hamilton- Buchanan & Gangetic provinces & Perciformes & Channidae \\
\hline 20 & Channa striatus & Bloch & Malabar & Perciformes & Channidae \\
\hline
\end{tabular}

Meristic counts: D- iii, 13; P- ii, 12; V- i, 8; A- iii, 5; C- 19; LLS- 39; PDS- 17; LL/D- 81/2; LL/V- 51/2; LL/A- 51/2; PRPLS- 9; PRAS- 25. Metric characters: TL (mm)- 156.0; SL (mm)- 115.0; HL (mm)42.0. \% SL: HL- 36.5; BDD-35.7; BDA-18.3; BWD-16.5; BWA-10.4; HD-28.7; HW- 20.0; PRD55.7; PRPL-54.8; PRA-82.6; POD-52.2; PRP-34.0; LP-21.7; LPL- 22.6; LA-21.7; LC-35.7; LCP16.5; DCP-14.0; WCP-6.1; DP-PL-22.6; DPL- A- 28.7; DA- C-20.9; LD-28.7; LBD-27.0; DAV-4.3; DVV-22.6. \% HL: HD- 78.6; HW- 54.8; ED-26.2; STL-28.6; WGM-28.6; IOW-40.5; 1NW-28.6.

Remarks: It may be one of the largest fishes residing in various water bodies of Kerala. It is widely distributed throughout India, Pakistan, Burma, Nepal and Bangladesh.

Cultivation: Catla catla feeds on planktons and decaying matter [9], [10]. It is the fastest growing Indian major carp species, growing to a very large size, 8- 10 kilograms. It was reported [11], [12] that they grow to a length of $29.5 \mathrm{~cm}$ to $68.5 \mathrm{~cm}$ and weight of 3.2 to $4.1 \mathrm{~kg}$ in the first year of cultivation. 


\subsection{Labeo rohita (Hamilton- Buchanan)}

Cyprinus rohita, Hamilton- Buchanan, 1822, Fishes of Ganges: 301, 388 (type locality: Gangetic Provinces).

Synonyms: Cyprinus rohita; Labeo horai

Diagnosis: Barbels are single pair of maxillaries which are concealed in the lateral groove; mouth sub terminal; $61 / 2$ scales between lateral line and dorsal and anal fins; lateral line straight; anal tip reach near to caudal base.

Meristic counts: D- iii, 11; P- i,17; V- i, 8; A- ii, 5; C- 19; LLS- 41; LL/V- 61/2; LL/D- 61/2; LL/A- 51/2; PDS- 13; PRPLS- 15; PRAS- 30. Metric chartacters: TL (mm) - 176.0; SL (mm)- 137.0; HL (mm)39.0. \% SL: HL- 28.5; HD-19.7; HW- 16.1; BDD-28.5; BDA- 16.8; BWD-17.5; BWA-11.0; PRD50.4; POD-57.0; PRP-27.0; PRPL-51.8; PRA- 78.1; LBD- 21.2; LBA- 6.6; LBC-13.1; DP- PL-27.0; DPL- A- 27.0; DA-C- 21.7; LC-28.5; LCP-16.1; DCP- 13.1; WCP-5.1; DVV-21.2; DAV- 5.8. \% HL: HD- 69.2; HW-56.4; ED-28.2; STL-28.2; WGM-30.8; IOW-46.2; INW-35.8.

Remarks: Rohu is the natural inhabitant of river systems of India, Nepal, Pakistan, Bangladesh and Burma. In recent years it has been transplanted to many countries of the world including Sri Lanka, Mauritius, USSR, Japan, Philippines, Laos, Malaysia and Thailand. This fish was originally described from River Ganges. L. rohita grows to $90.0 \mathrm{~cm}$. It was reported that it reached a length of $38.0 \mathrm{~cm}-$ $48.0 \mathrm{~cm}$ and weight of $680 \mathrm{gm}$ in the first year of cultivation. It was also recorded [13] that they reach sexual maturity in the first year itself.

\subsection{Labeo gonius (Hamilton, 1822)}

Cyprinus gonius Hamilton, 1822, Fish. Ganges: 292, 387 (Type locality: Freshwater rivers and ponds of Bengal)

Synonyms: Cyprinus gonius Hamilton, 1822; Rohita gonius Hamilton, 1822; Labeo microlepidotus Valenciennes, 1842; Osteochilus chalybeatus (Valenciennes, 1842); Rohita microlepidota (Valenciennes, 1842); Rohita chalybeata Valenciennes, 1842.

Diagnosis: One pair of small maxillary and rostral barbels present; dorsal fin with fourteen branched rays; $13 \frac{1}{2} 2$ scales between lateral line and dorsal fin. Lateral line scales $65+3$; Pre dorsal scales 25 .

Meristic counts: D- ii, 14; P- i, 16; V- I, 8; A- ii, 5; C- 19; LLS- 65+ 3; LL/D- 131/2; LL/V- 101/2; LL/A- 81/2; CPS- 13; PDS- 25; PRPLS- 20; PRS- 44. Metric characters: TL (mm)- 307; SL (mm)245; \% SL: HL- 23.3; BDD- 29.2; BDA- 18.8; BWD- 18.8; BWA- 11.0; HD- 20.4; PRD- 43.7; POD55.1; PRPL- 50.2; LP- 19.6; LD- 19.0; LPL- 17.5; LA- 16.3; LC- 25.3; LBD- 24.2; LBA- 8.6; DPPL- 29.2; DPL- A- 30.2; DA- C- 21.6; LCP- 14.1; DCP- 16.0; DVV- 112.3; DAV- 201.7; HL (mm)57.0; \% HL: HD- 87.7; HW- 69.3; ED- 20.2; STL- 27.2; IOW- 50.0; INW- 36.0; DOC- D- 119.3; DOC- ST- 72.0; POC- D- 50.8; HL- STL- 72.8.

Other Characters: Ventral fin inserted below anterior $1 / 3$ of the base of dorsal fin; anal fin tip reach to base of caudal fin; outer margin of dorsal and anal fins concave, of other fins convex;

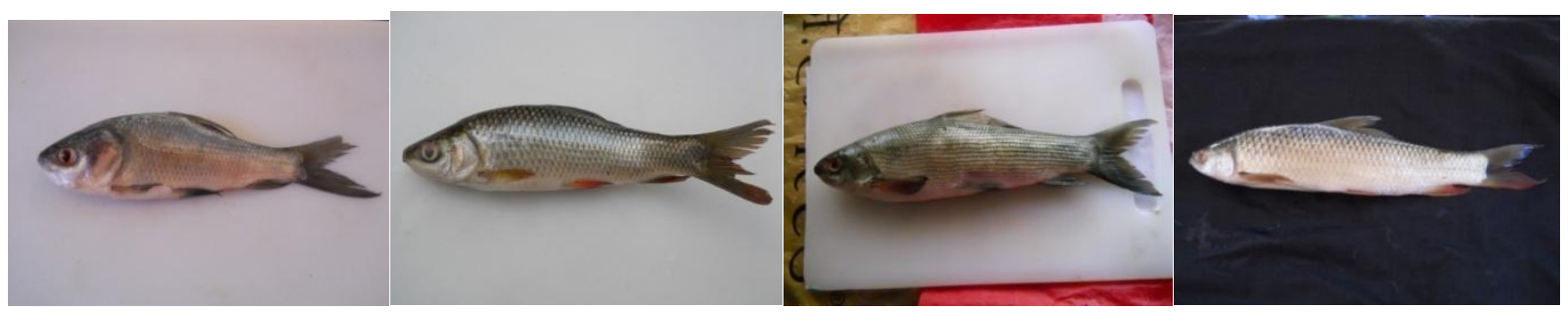

Fig. 1. Catla catla

Fig. 2. Labeo rohita

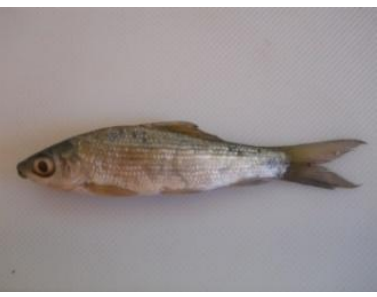

Fig. 5. Cirrhina cirrhosus Fig. 6. Cyprinus carpio communis Fig. 7. Systomus sarana

Fig. 3. Labeo gonius

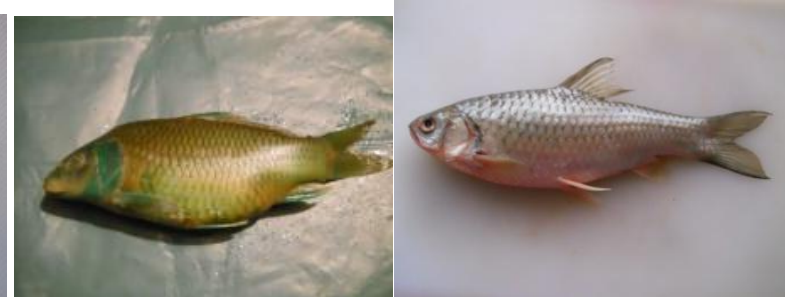

Fig. 4. Cirrhina mrigala

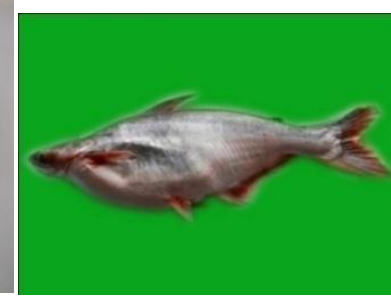

Fig. 8. P. hypothamus 


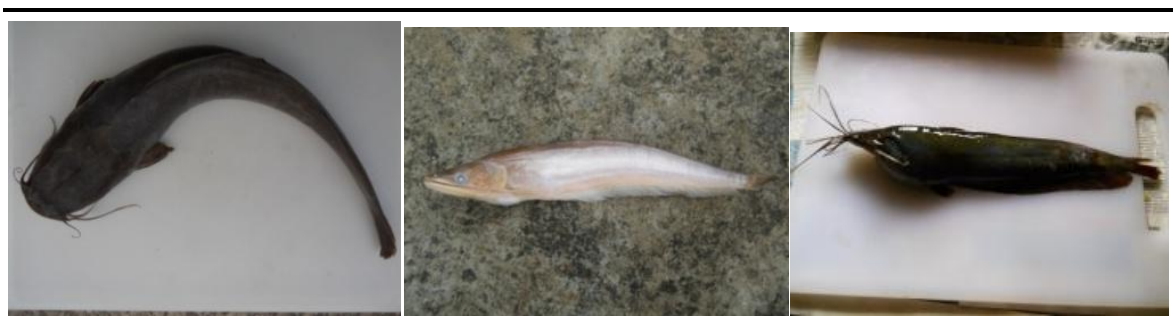

Fig.9. Clarias garipinus

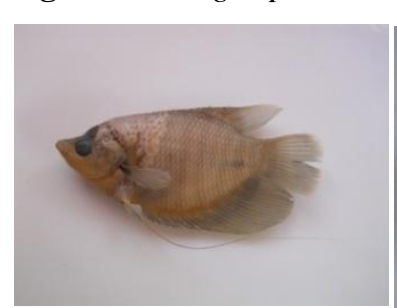

Fig. 10. Wallago attu

Fig. 11. Heteropneustes fossilis
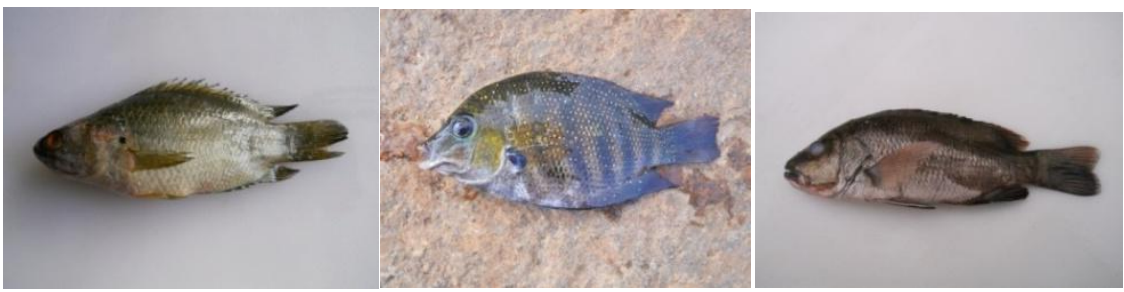

Fig. 13. Osphronemus goramy Fig. 14. Anabas testeudinus Fig. 15. Etroplus suratensis Fig. 16. Lates calcarifer


Fig. 17.Pristolepis rubripinnis Fig. 18. Channa marulius Fig. 19. Channa striatus Fig. 20. C. micropeltes

vent located an eye diameter distance from anal fin origin. 12 longitudinal lines present on the lateral sides of the body. It is commonly known as Kuria Labeo.

\subsection{Cirrhinus mrigala (Hamilton- Buchanan)}

Cyprinus mrigala Hamilton- Buchanan, 1822, Fishes of Ganges: 279, 386 (type locality: Ponds and freshwater rivers of Gangetic provinces).

Synonyms: Cyprinus mrigala; Cirrhina mrigala; Cirrhinus chaudhryi

Diagnosis: Two pairs of barbels- maxillaries and rostrals; ventral, anal and caudal fins reddish; Dorsal fin as high as body; pectoral fin shorter than head; lateral line with 43 scales.

Mereistic characters: D- iii- iv, 12- 13; A- iii, 5; P- i, 17; V- i, 8. Metric characters: TL (mm)- 325.0; SL (mm)- 280.0; HL (mm) - 30.0. \% SL: HL-10.7; BDD- 28.6; HD-21.4; PRD-45.0; POD-75.7; PRP53.6; LD- 22.5; LBD-18.9; LBA-7.1; LPL-16.1; LCP-14.3; DCP-11.8. \% HL: HD- 200.0; ED- 33.3; STL-53.3.

Remarks: Mrigal inhabits all the major river systems of India, Pakistan, Bangladesh and Burma. It was found [14] that edible flesh of Mrigal's body contains $18.10 \%$ protein and $2.55 \%$ fat.

\subsection{Cirrhinus cirrhosus (Bloch)}

Cyprinus cirrhosus Bloch, 1795, Natures. Ausland. Fische, 9: 52 (type locality: Cauvery River, Tamil nadu).

Synonyms: Cyprinus cirrhosus

Diagnosis: Dorsal profile convex but ventral profile straight; dorsal fin located far ahead of ventral fin and inserted nearer to snout tip than caudal base; anal tip reach near to caudal base; lateral line straight; mouth sub terminal and cresentic; one pair of small and delicate maxillary barbels which never reach eyes.

Meristic counts: D- ii, 12; A- ii, 5; P- ii, 15; V- i, 8, C- 21; LLS- 54; PDS- 21; LL/D- 111/2; LL/V71/2; LL/A- 71/2; PRPLS- 26; PRAS- 41. Metric characters: TL (mm) - 129.0; SL (mm)- 99.0; HL (mm)- 27.0. \% SL: HL- 27.3; HD- 19.2; HW-17.2; BDD-26.3; BDA-18.2; BWD-15.2; BWA-11.1; PRD-47.5; POD-59.6; PRP-25.3; PRPL-51.5; PRA-78.8; LP-19.2; LPL- 18.2; LA- 14.1; LC-31.3; LBC-11.1; LBA-9.1; DP- PL-27.3; DPL- A- 24.2; DA-C- 21.2; LCP-16.2; DCP-12.1; WCP-5.1; DVV- 22.2; DAV- 3.0. \% HL: HD- 70.4; HW-63.0; ED-33.3; WGM- 26.0; STL-33.3; IOW-44.4; INW-33.3. 
Remarks: it is a south Indian carp. According to Day [15] it naturally inhabits in the Cauveri, Krishna and Godavari Rivers. Its number and range has now been diminishing in South India [16], [17].

\subsection{Cyprinus carpio communis Linnaeus}

Cyprinus Linnaeus, 1758, Systema Naturae, Ed. 10, 1: 320 (type species, Cyprinus carpio Linnaeus, by subsequent designation; type locality; Europe).

Synonym: Cyprinus carpio intha

Diagnosis: Body is fairly deep. Dorsal profile more convex than ventral. Abdomen rounded. Snout obtuse. Well developed rostral and maxillary barbels present; maxillary barbels twice as long as rostral pair. Last unbranched dorsal and anal fin osseous and serrated. Caudal fin deeply emarginate.

Meristic counts: D- iii, 19; P- i, 15; V- i, 8; A- iii, 5; C- 19; LLS- 36; L/Tr- 8/51/2; PDS- 11; CPS- 5. Metric characters: TL (mm) - 300.0; SL (mm) - 235.0. \% SL: BDD- 40.4; HL-28.5; PRD- 56.2; POD48.9; PRP- 48.9; LD- 18.3; LBSD-36.6; LBA-9.4; LP-20.0; LPL-19.1; LCP-12.8; DCP-14.0; HL (mm) - 67.0; \% HL: HD-119.4; ED-13.4; STL-35.8.

Other features: Head triangular and rounded at the snout, with a small oblique, terminal, tubular and protrusible mouth having thick fleshy lips. Nostrils situated near to eyes and they have large pits. A number of minute grooves present on opercle. Pectoral fins large. Lateral line complete and concave. Color silvery. Dark spots present between scales give an appearance of having 8 lateral longitudinal lines; it takes a bright red color during breeding season; fins reddish; it turns to golden yellow after preservation in formalin.

Cultivation: Cyprinus carpio (common carp) is the most domesticated and cultivated carp species throughout the world. In India, this fish was imported from China and introduced into Nilagiri lakes. The growth of the fish is higher and grows to a length of $75 \mathrm{~cm}$ and $6.5 \mathrm{~kg}$ weight. It breeds thrice in a year. It was found that [18] it is not desirable to rear this fish along with major carps as it feed on the eggs of major carps.

\subsection{Systomus sarana (Hamilton- Buchanan)}

Cyprinus sarana Hamilton Buchanan, 1822, Fishes of Ganges; 307, 388 (type locality: Ponds and rivers of Bengal); Puntius sarana Jayaram, 1991, ZSI, Occ. Paper: 13, 113-123; Systomus sarana, Pethiyagoda et al, 2012, Ichthyol. Expl. Freshwaters, 23 (1): 69-95.

\section{Synonyms: Cyprinus sarana; Barbus sarana; Puntius sarana; Puntius saberi}

Diagnosis: Lateral line scales 32, pre dorsal scales 13 and body color silvery; depth of body 2.7 times in SL.

Meristic counts: D-iii, 8; A- iiii, 6; C- 19; V- ii, 8; P- i, 16; LLS- 32; L/Tr- 6/4; PDS- 13; CPS- 7. Metric characters: TL (mm)- 231.0; SL (mm)- 184.0; HL (mm) - 45.0. \% SL: BDD- 38.0; BDA-28.3; BWD- 10.3; HL-24.5; HD-19.6; HW- 11.9; PRD- 54.3; POD- 51.6; PRP- 27.2; PRPL-51.6; PRA78.8; LD- 4.; LP- 19.6; LPL- 19.0; LA-13.6; LBD-17.4; LBA-8.7; LBP- 5.4; LBPL- 5.4; LCP- 18.5; DCP-15.2. \% HL: HD- 19.6; HW-48.9; ED- 20.0; WGM- 6.7; IOW- 44.4; STL-24.4.

Remarks: Commercial cultivation of Systomus species is rare in Kerala. But the fries of Systomus species, collected along with other carps, are allowed to rear in ponds.

\subsection{Pangasinodon hypophthalmus (Sauvage)}

Helicophagus hypophthalmus, Sauvage, 1878. Bulletin de la Société philomathique de Paris (7th Séries) v. 2: 233-242.

Diagnosis: Head dorso- ventrally flattened; rest of the body laterally compressed; pelvic fins with 8 rays; maxillaries and mandibulars short; maxillaries never reach base of pectoral or outermost part of opercle.

Meristic counts: D- I, 7; P- I, i, 9; V- i, 7; A - iv, 29; C - 18. Metric characters: SL (mm)- 375.0; HL (mm) - 100.0; \% SL: HL - 26.7; BDD- 40.0; BDA-34.7; BWD-18.7; BWA-13.3; PRD-37.9; POD61.3; PRP- 22.9; PRPL-49.3; PRA-61.3; LAD- 5.6; LPL-12.3; LA-12.0; LBRD-7.2; LBA-29.1; LBP5.1; LBPL-5.9; LCP- 13.3; DCP-13.1; WCP- 6.1; DAV-1.1; DVV-9.8; \% HL: HD- 65.0; HW- 58.0; ED- 10.0; IOW- 55.0; STL- 35.0; LMB- 32.0; LOMB- 19.0. 
Other features: Snout length shorter than inter orbital width; barbels short and feeble; dorsal spine roughened externally and serrated internally; adipose dorsal is far back, short based and small. Pectoral spine deeply serrated internally and roughened externally. Tip of pelvic fin reaches anal fin.

Remarks: These are cultivated commercially in many ponds of Kerala. But they are erroneously identified as Pangasius sutchi. They reach up to $8-10 \mathrm{kgs}$; but their flesh is not favored by many due presence of excess fat.

\subsection{Clarias gariepinus (Burchell)}

Silurus gariepinus, Burchell, W. J. 1822. Travels in the interior of southern Africa. 2 vols. London. v. 1: i-xi + 1-582 + 1-4, 1 Map.; v. 2: 1-648. [Fishes in v. 1: 280, 284, 425, 445.]

Diagnosis: Cephalic groove divided into two fontanels; of this, anterior one is elongated and posterior one is round and deep; in addition to this a small groove present on occiput also; occipital process never reach dorsal fin front; nasal barbels short and never reach occiput; maxillaries and outer mandibulars reach just behind pectoral base, inner mandibulars never reach pectoral base. Tip of pelvic fin reach behind the origin of anal fin. Dorsal and anal fin long but never fused to caudal.

Meristic counts: D- 63; P- I, 8; V- 6; A- 52; C- 19. Metric characters: TL (mm)- 352.0; SL (mm)307.0; \% SL; HL- 21.5; HD-11.4; HW-18.6; BDD-14.0; PRD-30.5; POD-63.5; LD-3.3; LBA-44.0; LP-10.7; LPL-11.1; LA-5.2; LC-14.6; DP- PL- 22.1; DPL- A- 9.4; DAV- 3.3; DVV- 4.6; HL (mm)66.0; \% HL: HD-53.0; HW-86.4; ED-10.6; STL-37.8; IOW-48.5; INW-34.8; LMB-92.4; LNB-47.0; LOMB-74.2; LIMB-55.3.

\subsection{Wallago attu (Bloch \& Schneider)}

Silurus attu Blotch \& Scheiner, Syst. Ichthyol. 378 (type locality: Malabar).

Synonyms: Silurus attu; Wallagonia attu; W. attu valeya

Diagnosis: Mouth is oblique and cleft of mouth extends beyond the orbit. Maxillaries extend well beyond origin of anal fin; pectoral spine weak, poorly serrated on its inner edge. Caudal fin deeply forked and its upper lobe longer.

Meristic counts: D- 5; P- I, 13- 15; V-i, 7- 9; A-iii, 74- 93. Metric characters: TL- 303.0; SL- 270.0; HL- 5.9. \% SL: HL-21.8; HD-14.1; HW-11.8; BDD-16.3; BDA-14.4; BWD-9.6; PRD-27.4; POD68.5; PRP-20.4; PRPL-33.0; PRA-40.7; LD-14.8; LP-14.8; LPL-7.0; LA-3.0; LC-11.0; LBD-1.5; LBP-3.3; LBPL-2.6; LBA-57.4; LBC-4.4; LCP-1.8; DCP-4.4; WCP-1.1; DP- PL-14.1; DPL-A-7.4; DA- C-59.3; LUCL-12.2; LLCL-9.6; DO- ST-14.1; DO-D-16.0. \% HL: HD- 64.4; HW-54.2; ED11.8; IOW-44.1; INW-20.3; WGM-47.5.

Remarks: Wallago attu is cultivated in freshwater pond commercially. They reach to 8- $10 \mathrm{kgms}$. Their flesh is palatable and it fetch high prize in market.

\subsection{Heteropneustes fossilis (Bloch)}

Silurus fossilis, Bloch, 1794, Naturg. Ausland Fische 8; 46 (type locality: Tranquebar).

Synonyms: Silurus fossilis; Sacchobranchus fossilis

Diagnosis: Head depressed; median frontal groove on head limited to a round depression between and backwards of eyes; occipital process short and not extending to base of dorsal fin; rayed dorsal fin is short and without a spine; anal fin long based, separated by a distinct notch from caudal fin; pectoral fin with strong serrated spine; caudal fin rounded.

Meristic counts: D- 6-7; P- I, 7; V- i, 5; A- 60- 70. Metric characters: TL (mm)- 171.0; SL (mm)150.0; HL (mm)- 29.0. \% SL: HL- 19.3; HD-10.0; HW-16.0; BDD-20.0; BWD-15.3; PRD-32.7; POD-68.7; PRP-16.7; POD-68.7; PRP-16.7; PRPL-35.3; PRA-40.7; LD-11.3; LP-13.3; LPL-8.7; LA10.7; LC-14.0; LBD-40.0; LBP 26.7; LBPL-18.0; LBA- 48.7; LBC-40.0; DP-PL-21.3; DPL-A-40.; \% HL: ED-13.8; IOW-48.3; INW-27.6; WGM-38.0; DO-ST-82.8; DO-D-86.2.

Other features: Body elongate and sub cylindrical to pelvic base, compressed behind. body yellow above and on lateral sides, lighter below; dorsal located a little in front of pelvic; pectoral never reach pelvic fin, the latter reach behind anal origin; anal never fused to caudal. 
Heteropneustes fossilis, the Asian stinging catfish, is a species of air sac catfish found in India, Bangladesh, Pakistan, Nepal, Sri Lanka, Thailand, and Myanmar. They are rarely cultivated commercially. But in Central Travancore regions they are reared in many ponds.

\subsection{Oreochromis (Tilapia) mossambica (Peters)}

Chromis mossambicus Peters, Montab. Akad. Wiss., Berlin: 681 (type locality: Mozambique).

Synonyms: Chromis mossambica, Tilapia mossambica

Diagnosis: It can be readily identified by its blackish blue coloration and its fins that are beautifully bordered with red. Its large head and wide mouth are further evidences. Dorsal and anal fins have prolonged and pointed tips and the tail is round. Lateral line scales 31. Dorsal fin with 17 spines and anal fin with 3 spines.

Meristic counts: D- XVII, 11; A- III, 9; V- I, 5; P- I, 12;C- 15;LLS- 31 (16/15); PDS- 9; CPS- 7. Metric characters: TL (mm) -263.0; SL (mm)- 215.0; HL (mm) -70.0; \% SL: HL-32.6; HD-37.2; BDD-38.6; PRD-35.3; POD-61.4; PRP-67.4; LD-25.6; LP-30.2; LPL-28.0; LBSD-21.8; LBA-20.0; LCP-16.3; DCP-14.0; \% HL: HD-114.3; ED-17.1; STL-35.7.

Other features: Three or four blotches present along the flanks; teeth are in 3- 5 rows on jaws. Head compressed with concave upper profile; spinous portion of dorsal fin is longer than soft part. It was imported from East Africa in 1952. Its growth rate was found to be rapid in the first 6- 8 weeks and then it is slow [19]. Reproductive potential of Tilapia varies with the size of the fish [20]. It was found that monosex culture [21] and paddy cum fish [22] culture of Tilapia was found lucrative.

\subsection{Osphronemus (Osphromenus) goramy Lacepede}

Osphronemus goramy Lacepede, 1801, Hist. Nat. Poiss., 3: 116 (type locality: Mauritius). Osphronemus goramy Roberts, 1992. Revision. Ichthyol. Explor. Freshwat. 2(4):351-360.

Synonyms: Osphromenus goamy; Osphronemus olfax; Osphronemus notatus; Osphronemus satyrus

Diagnosis: 12 dorsal spines and 10 anal spines; 1 ventral spine; $2^{\text {nd }}$ ray of pectoral fin elongated to form very long filament extending beyond caudal fin; inter orbital region fairly concave.

Meristic counts: D- XII, 11; P- 13; V- I, i, 4; A- X, 20; C- 16; LLS- 34+3; L/Tr- 61/2/121/2; LL/D- 61/2; LL/V- 121/2; CPS- 51/2/41/2; LL/A- 121/2; VR- 31. Metric characters: TL (mm)- 175.0; SL (mm) 135.0; \% SL: HL- 32.6; HD-31.8; HW-17.8; BDD-49.6; BDA-44.4; BWD-16.3; PRD-47.3; POD51.8; PRP-32.6; PRPL-40.0; PRA-50.4; LD- 26.7; LP-23.7; LPL-23.7; LSOA-6.0; LBSOD-26.7; LBA-55.6; LBP- 6.0; LBPL-3.7; LCP-6.0; DCP-17.0; WCP-2.9; DAV-3.0; DVV-7.4.

Other features: Soft dorsal fin elongated and reach to middle of caudal fin; anal and ventral fin located close to each other. Tip of pectorals reach 5-6 anal spine; soft anal fin broad and elongated, reach to hind part of caudal fin. A black blotch presents at the base of pectoral fin; inter orbital region fairly concave. It was imported from Jawa and Maritius and introduced into fresh waters of Madras and Calcutta. The rate of growth Gouramy was found to be very slow. Its spawning occurs mostly during April, May months [23].

\subsection{Anabas testudineus (Bloch)}

Anthias testudineus, Naturges. Ausland. Fische, (6); 121 (type locality: Java).

Synonyms: Anthias testudineus; Anabas scandens; A.t. riveri; A. t. lacustri; A. t. ricei

Diagnosis: 21- 29 scales present along the lateral series; operculum serrated with spines; mouth large with small conical teeth; a black spot present at the base of pectoral fin.

Meristic counts: D- XVIII, 9; A- XI, 9; P- 16; V- I, 5. Metric characters: TL (mm)- 127.0; SL (mm)101.0; HL (mm)- 34.0. \% SL: HL-33.7; HD-25.7; HW-23.8; BDD-31.7; BDSOA-28.7; BWD-21.8; BWSOA-9.9; PRD-35.6; POD-67.3; PRP-34.7; PRPL-40.6; PRA-57.4; LSOD-14.8; LP- 20.8; LPL17.8; LSOA-13.8; LC-25.7; LBD-58.4; LBP-6.9; LBPL-4.9; LBA-36.6; LBC-14.8; LCP-8.9; DCP14.8; WCP-3.9; DP-PL-9.9; DPL- A-18.8. \% HL: HD- 76.5; HW- 70.6; ED-20.6; IOW-35.3; INW20.6; WGM-29.4; DO- ST- 73.5; DO-D-35.2.

Other features: Body oblong and compressed at the posterior region; it is greenish to dark grey on dorsal side and flanks and ventral side pale yellow; a well marked blotch is seen at the base of caudal 
peduncle; pectoral and anal fins pale yellow; dorsal and caudal fins dark grey. Anabas testeudineus is a native to Asia. It has also been introduced in some countries outside of its natural limit. This species grows to $25 \mathrm{~cm}$ in total length. It is rarely cultured in the water bodies of Kerala.

\subsection{Etroplus suratensis (Bloch)}

Chaetodon suratensis Bloch, 1785, 1785, Syst. Ichth: 427 (type locality: Surat).

Synonym: Chaetodon suratensis

Diagnosis: Five to six slanting black bands present on the body; each scale with a fluorescent pearly spot on it; pectorals with a large black spot at the base; dorsal fin with 18 spines; anal with 12 spines.

Meristic counts: D- XVIII, 15; P- 14; V- I, 5; A- XII, 13; C- 16;.LLS- 43; PDS- 13; LL/D- 81/2; LL/V18; LL/A- 201/2; PPLS- 15; PRA- 25;

Metric characters: TL (mm)- 160.0; SL (mm)- 131.0; HL (mm) - 40.0. \% SL: HL- 30.5; HD-40.4; BDD-50.4; BDA-56.5; BWD-20.6; BWA-20.6; PRD-41.9; POD-62.6; PRP-33.6; PRPL-36.6; PRA52.0; LDSP-10.7; LSOD-19.8; LP-23.7; LPL-17.6; LASP-11.4; LBSPD-46.6; LBSOD-18.3; LBP7.6; LBPL-4.6; LBSPA-30.5; LCP-6.8; LC-19.8; LBSOA-15.3; DCP-15.3; WCP- 3.0; DPL-A-16.0; DA-C-54.2. \% HL: HD- 132.5 ED- 22.5; IOW-40.0; INW-15.8; STL-45.0; WGM-22.5.

Other features: Lateral line is interrupted after 21 scales; color blackish green; scales on ventro lateral sides of the body deep black; dorsal fin arise above the commencement of pectoral; scales are ctenoid which are absent on snout and inter orbital region.

Etroplus Suratensis is a species of cichlid fish found in both freshwater and brackish water bodies in southern India and Sri Lanka. It is a good fish for aquaculture. In India, it is found throughout Kerala and in western flowing rivers in Karnataka, backwaters of Andhra Pradesh and Chilika Lake. It has been cultured in many water bodies of Kerala successfully.

\subsection{Pristolepis rubripinnis Britz et al.}

Pristolepis rubripinnis, Britz et al. 2012, Zootaxa 3345: 59-68 (Type locality: Pamba and Chalakudy Rivers).

Diagnosis: Fins orange red; three spines in anal fin and 14- 15 spines in dorsal fin; eyed reddish.

Meristic counts: D- XIV-XV, 13-14; P- 13-14; P- I, 5; A- III, 9; C- 14; LLS- 28-29; LL/D- 41/2; LL/V- 101/2; L/Tr- 41/2/101/2; PDS- 19-20; C- 41/2. Metric characters: SL (mm)- 87-110; \% SL: BDD43.00-43.68; BDA-44.00-45.9; BWD-20.69-23.00; BWA-11.82-17.24; HL- 34.54-39.08; HD-33.1837.89; HW-20.69-22.00; PRD- 39.00-42.53; POD-65.45-70.00; PRP-35.5-37.36; PRPL-41.82-42.00; PRA-71.00-78.16; LSPD-11.49-11.82; LSOD-21.84-23.64; LP-24.5-25.45; LPL-21.82-25.29; LSOA22.22-29.09; LBSPD-46.81-49.00; LBSOD-14.94-18.18; LBA- 21.84-23.00; LCP-9.19-13.64; DCP4.00-17.27; WCP-3.00-4.09; DAV-5.91-6.8; DVV-26.36-31.03. \% HL: HD-95.59-98.65; HW-52.9463.16; ED-23.53-26.32; IOW-28.95-29.73; INW-16.18-21.05; STL-21.62-26.32; WGM-23.03-27.63.

Remarks: It is fairly common in the low level regions of Manimala River. At some mid level regions it is found along with $P$. malabarica; but the $P$. rubripinnis may grow up to $0.75 \mathrm{~kg}$, but $P$. malabarica only up to $200 \mathrm{gm}$.

\subsection{Lates calcarifer Bloch}

Holocentrus calcarifer Bloch, 1790, Naturges, ausland. Fische, (4): 100 (Type locality: Indonesia).

Synonym: Holocentrus calcarifer

Diagnosis: Dorsal and anal fins with strong spines; pelvic fin with a thin but strong spine; pelvic fin originate just below pectoral fin; tip of anal reach caudal base; mouth with canine teeth.

Meristic counts: D- X, 14; P- i, 14; V- I, 5; A- III, 9; C- 17; LLS- 50; PDS- 16; PPLS- 9; PRAS- 25; LL/V- 16; LL/D- 6; LL/A- 14. Metric characters: TL (mm)- 199.0; SL (mm)- 161.0; HL (mm) - 59.0. \% SL: HL- 36.7; HD-28.6; HW-19.8; BDD-34.8; BDA-14.3; BWD-21.1; BWA-30.4; PRD-46.0; POD-62.7; PRP-37.8; PRPL-41.6; PRA-69.6; LP-30.4; LPL-20.5; LC-24.2; LSPD-13.0; LSOD-13.0; LBSPD-35.4; LBSOD-17.4; LBA-16.1; LCP-18.0; DCP-12.4; DPL-A-30.4; DA-C-34.1; DVV-24.2; DAV-6.2. \% HL: HD- 78.0; HW-54.2; ED- 27.1; WGM-32.2; STL-32.2; IOW-22.0; INW-22.0. 
Remarks: It is an estuarine species; it usually descends to rivers. It grows to a size of $60 \mathrm{~cm}$ and may reach to a size of $150 \mathrm{~cm}$.

\subsection{Channa marulius (Hamilton- Buchanan)}

Ophiocephalus marulius Hamilton- Buchanan, 1822, Fishes of Ganges: 65, 367 (type locality: Gangetic provinces).

Synonyms: Ophiocephalus marulius, Ophiocephalus leucopunctatus, Ophiocephalus pseudomarulius, Channa marulius ara

Diagnosis: A black white edged ocellus present on upper part of basal portion of caudal fin. Large black blotches adorn the sides of the long body. sixty six scales present on the lateral sides of the body. Sixteen scales present before the dorsal fin.

Meristic counts: D- 49; P- 18; V-7; A- 32; C- 14.LLS- 66. Metric characters: TL (mm) - 24.0; SL (mm) - 20.0. \% SL: HL- 32.5; HD-25.6; BDD-16.5; PRD-34.4; POD-64.4; PRP-36.7; LD- 8.9; LBD64.4; LBA-33.3; LP-16.7; LPL-12.2; LCP-8.0; DCP-10.6.

Other features: Five or six dark blotches present on the lateral sides of the body. White spots are scattered over the body; fins are mottled with white spots.

\subsection{Channa striatus (Bloch)}

Ophiocephalus striatus Bloch, 1793, Natures. Ausland. Fische, (7): 141 (type locality: Malabar).

Synonyms: Ophiocephalus striatus

Diagnosis: Seventeen scales present before dorsal fin; lateral line scales 56. Dark oblique bands pass from ventral surface up to the lateral line; caudal fin with two distinct vertical bands at its base.

Meristic counts: D- 44; P- 15; V- 6; A- 25; C- 13; LLS- 56; LL/D- 4 1/2; LL/V- 7 1/2; PDS-17; LL/A11; PRPS- 6; PRPLS- 10; PRAS- 25; CPS- 10. Metric characters: TL (mm) - 220.0; SL (mm)- 180.0; HL (mm) - 62.0. \% SL: BDD- 25.0; HL- 34.4; HD-25.6; PRD-34.4; POD-64.4; PRP-36.7; LD- 8.9; LBD-64.4; LBA-33.3; LP-16.7; LPL-12.2; LCP-7.2; DCP-10.6. \% HL: HD-74.2; ED- 13.0; STL16.1 .

Other features: Belly pure white; fins spotted; dorsal and anal fins have a dark stain; head elongated; mouth superior; jaws sub equal; lateral line curves downward in the 12th scale.

Remarks: Channa striatus is a widely distributed species of snakehead fish; but in specimens collected from water bodies of Kollam showed some differences; in them D- 38; P- 16; A- 26; LLS57; PDS-14; examination of type specimens is inevitable to solve this problem.

\subsection{Channa micropeltes (Cuvier)}

Ophiocephalus micropeltes Cuvier, Hist. Nat. Poiss., 7: 427 (type locality: Java).

Synonym: Ophiocephalus micropeltes

Diagnosis: Dorsal fin with 42 and anal fin with 25 rays; lateral line scales 102; minute brownish spots present on body.

Meristic counts: D- 42; V- I, 6; P- 16; A- 25; C- 14; LLS- 102; PDS- 22; CPS- 13. Metric Characters: TL (mm)- 235.0; SL (mm)-193.0; HL (mm) - 66.0. \% SL: HL-34.2; HD-16.6; BDD-16.6; PRD-27.5; POD-69.0; PRP-36.8; LD-7.3; LP-12.0; LPL-10.8; LBD-62.2; LBA-36.8; LCP-10.4; DCP-10.4. \% HL: HD-48.5; ED-12.1; STL-22.7.

Other features: Dorsal and dorso lateral sides are greenish dark; ventral and ventro lateral sides yellowish; dorsal and caudal fins with a light dark color; pectoral and pelvic fin yellowish; eyes are protruding.

Remarks: Young one morphologically different to adults; in young ones 2 black horizontal stripes run from the tip of head to caudal tip; of these upper one starts from the middle of the eye and reach middle part of caudal fin; the lower stripe starts from the lower part of upper jaw and ends in the middle of caudal fin. Adults devoid of any lateral bands. 


\section{Conclusion}

Taxonomic studies are helpful in the correct identification and description of species. Studies on the meristic and morphometric features of a fish are helpful in the correct classification of it. Analysis with a few characters may not give a clear picture about the taxonomical status. Analysis with more relevant variables can alone trace the taxonomic position. Careful analysis of detailed meristic and morphometric characters from more number of specimens may help to collect greater number of distinctions between species and so correct identification. Pangasinodon hypophthalmus is a common exotic cultivated fish species of India. But they are mistakenly identified as Pangasius sutchi. We cannot find its correct scientific name in taxonomic literature available in India. Detailed taxonomic analysis helped to prove their identity. Cirrhina mrigala, Catala catla, Labeo rohita and Labeo gonius were originally described from west Bengal. To find out the correct taxonomic status of these fishes, specimens of these from their type locality is inevitable. Likewise, specimens of Cirrhinus cirrhosus from Cauvery River of Tamil Nadu (type locality) is essential to find out the species level identification of similar specimens of Cirrhinus species from Kerala. It is expected that more taxonomical studies will help to reveal many hidden scientific facts in future.

\section{ACKNOWLEDGEMENT}

The author acknowledges Principal, Baby John Memorial Government College, Chavara, Kerala for providing the facilities. I am also grateful to anonymous reviewers for comments that helped to improve the manuscript.

\section{REFERENCES}

[1] Jhingran, V. G, Fish \& Fisheries of India. Hindustan Publishing corporation. 1974., 954.

[2] Agarwal, S. C, A hand book of Fish Farming. Narendra Publishing House, Delhi, 2007, 134.

[3] Jayaram, K. C, The freshwater fishes of India: A hand book. Zoological survey of India, Kolkata, 1981, 1- 475 .

[4] Jayaram, K. C, Revision of the genus Puntius Hamilton from Indian region. Records of zoological survey of India, occasional paper no.13, Zoological Survey of India, Kolkata, 1991, 113-123.

[5] Jayaram, K. C, Fresh water fishes of the Indian region. Narendra publishing House, Delhi, 1999, 234.

[6] Jayaram, K. C, Fundamentals of fish taxonomy. Narendra publishing House, Delhi, 2002, 53-65.

[7] Jayaram, K. C, Cat fishes of India, Narendra Publishing House, Delhi, 2006. 41- 145.

[8] Jayaram, K. C, Fresh water fishes of the Indian region. Narendra publishing House, Delhi, 2010, 292.

[9] Alikunhi, K. H, Fish Culture in India. Farm bulletin. No. 20, ICAR, New Delhi, 1957.

[10] Hora, S. L \& Pillai, T. V. R, Hand Book on fish culture in Indo Pacific region- FAO Fish Culture. No.14. 1962.

[11] Chacko, P. I, Observations on the biology of inlanf water fishes on Madras with special reference to their suitability for culture. Fisheries student's reports \& year book 1954- 55, Department of Fisheries, Madras state, 1956.

[12] Khan, M. A, Production Biology of riverine fish. Inland Fisheries Society of India, 1989, 4251.

[13] Sukumaran, K. K, Growth, maturation and fecundity of cultivated fishes. FAO/UNDP. Reg. Seminar on I. B. of cultivated fishes. FRI/ IBCF/5, 1969.

[14] Nadarajan, M. V. \& Sreenivasan, A, Proximate mineral composition of freshwater fishes. Indian Journal of fisheries, 1961, 3: 422- 429.

[15] Day, F, Fishes of India, being a natural history of fishes known to inhabit the seas and freshwaters of India, Burma and Ceylon, 1878, 778

[16] Menon, A. G. K, Check list of fresh water fishes of India. Records of Zoological Survey of India, Occasional Paper, 1999, 175: 212.

[17] Menon, A. G. K, Threatened fishes of India and their conservation. Zoological Survey of India, Kolkata, 2004, 1- 170. 
[18] Panicker, N. K, Fry of Chanos chanos. Current Science, 1952, 21:1.

[19] Menon, M. D, Murthi, B. K. \& Ramachandran On the possible forage fish Tiulapia mossambica and its growth; Fish- Stu- Reports \& Year Book, Dept of Fisheries Madras, 1959.

[20] Panicker, N. K. \& Thampi, P.R.S, on the mouth breeding Ciclid Tilapia mossambica (Peters). Indian Journal of Fisheries, 1954, 1: 1-2.

[21] Kong, C. P, Monosex culture of Tilapia mossambica in ponds at Mautting farm Keningau Dist, North Borneo- Indo- Proce- Fish- Cul10th, 1962, 164- 169.

[22] Umpol P. S, Progress of Ricefield fish culture in Thailand; Indo- Paci- Fish- Com, 1962, 10: 157- 163.

[23] Kulkarni, C. V, Gourami Culture Ind- farming, 1946, 3: 12. 